\title{
Zinc oxide nanocolloids prepared by picosecond pulsed laser ablation in water at different temperatures
}

\author{
Luisa D'Urso, ${ }^{1,}$, Salvatore Spadaro ${ }^{2}$, Martina Bonsignore $^{2}$, Saveria Santangelo ${ }^{3}$, Giuseppe Compagnini ${ }^{1}$, \\ Fortunato $\mathrm{Neri}^{2}$, and Enza Fazio $^{2 *}$ \\ ${ }^{1}$ Dip. di Scienze Chimiche, Università di Catania, Catania, Italy \\ ${ }^{2}$ Dip. di Scienze Matematiche e Informatiche, Scienze Fisiche e Scienze della Terra (MIFT), Università di Messina, 98166 \\ Messina, Italy \\ ${ }^{3}$ Dip. di Ingegneria Civile, dell'Energia, dell'Ambiente e dei Materiali (DICEAM), Università Mediterranea, 89122 Reggio Calabria, \\ Italy
}

\begin{abstract}
Zinc oxide with wide direct band gap and high exciton binding energy is one of the most promising materials for ultraviolet (UV) light-emitting devices. It further exhibits good performance in the degradation of non-biodegradable pollutants under UV irradiation. In this work, zinc oxide $(\mathrm{ZnO})$ and zinc oxide/gold $(\mathrm{ZnO} / \mathrm{Au})$ nanocolloids are prepared by picosecond pulsed laser ablation (ps-PLA), using a $\mathrm{Zn}$ and $\mathrm{Au}$ metallic targets in water media at room temperature (RT) and $80^{\circ} \mathrm{C}$. $\mathrm{ZnO}$ and $\mathrm{Au}$ nanoparticles (NPs) with size in the $10-50 \mathrm{~nm}$ range are obtained at RT, while $\mathrm{ZnO}$ nanorods (NRs) are formed when water is maintained at $80^{\circ} \mathrm{C}$ during the ps-PLA process. Au NPs, added to $\mathrm{ZnO}$ colloids after the ablation process, decorate $\mathrm{ZnO}$ NRs. The crystalline phase of all $\mathrm{ZnO}$ nanocolloids is wurtzite. Methylene blue dye is used to investigate the photo-catalytic activity of all the synthesised nanocolloids, under UV light irradiation.
\end{abstract}

\section{Introduction}

Photo-catalysis has been emerged as a viable route to decrease the damage caused by dye pollution to environment and humans [1]. The removal of persistent and toxic organic compounds (TOCs) from contaminated water occurs through oxidation and reduction processes. Several kinds of semiconductor-based photo-catalysts, such as titania $\left(\mathrm{TiO}_{2}\right)$, zirconia $\left(\mathrm{ZrO}_{2}\right)$, tungsten trioxide $\left(\mathrm{WO}_{3}\right)$, tantalum pentoxide $\left(\mathrm{Ta}_{2} \mathrm{O}_{5}\right)$, hematite $\left(\mathrm{Fe}_{2} \mathrm{O}_{3}\right)$ and zinc oxide $(\mathrm{ZnO})$, have been applied in wastewater treatment to convert non-biodegradable TOCs into nontoxic chemicals under UV irradiation $[2,3]$.

Among them, $\mathrm{ZnO}$ looks as a very promising candidate for environmental applications because it is cheap, and has a great photo-catalytic activity, a strong oxidation ability, a direct and wide band-gap energy in the near-UV spectral region $(3.3 \mathrm{eV}$ at $300 \mathrm{~K})$, higher quantum efficiency compared to other wide band-gap semiconductors, and a large free-exciton binding energy $(60 \mathrm{meV})$ so that exciton emission processes can persist at or even above the room temperature. Moreover, being compatible with living organisms, $\mathrm{ZnO}$ is currently employed in a broad range of daily applications without risks to human health and environmental impact [4].

Many works in the literature deal with the utilisation of $\mathrm{ZnO}$ for UV lasers, high power light emitting diodes, solar cells, heterogeneous catalysis and antibacterial treatments and the effective degradation of harmful and toxic pollutants present in the wastewater [5].
Nonetheless, the photo-catalytic activity of $\mathrm{ZnO}$ nanomaterials is limited under the sun irradiation because the solar spectrum contains only $5-7 \%$ of the UV component. The relatively high recombination rate of generated electron-hole pairs also reduces the efficiency of this photo-catalyst. A large number of factors, such as crystallinity, crystallite size, crystal phase, and porosity, as well as specific surface area, can further affect the performance of $\mathrm{ZnO}$ [6].

Different strategies have been employed in order to improve the photo-catalytic performance of semiconductor materials. The nanostructuration, resulting in a high surface-area/volume ratio, enhances the amount of the photo-generated charge carriers, whereas the addition of metal NPs on the photo-catalyst surface reduces recombination rate of the excited photoelectron-hole pairs. Gold NPs have been successfully utilised by several groups. The addition of $\mathrm{Au}$ NPs shifts the optical absorption into the visible region, hence enabling a more efficient utilisation of the solar energy. Au NPs can act as a sink for photo-induced charge carriers, thus promoting interfacial chargetransfer processes. Moreover, receiving electrons from the $\mathrm{Au}$ NPs surface, oxygen can trap electrons and becomes the active $\mathrm{O}_{2}^{-}$species with consequent enhancement of the photo-catalytic activity [7].

In this paper, we propose a simple and cheap physical approach to the synthesis of $\mathrm{ZnO}$ and $\mathrm{Au}-$ decorated $\mathrm{ZnO}$ nanorods with no environmental impact.

Corresponding author: 1durso@unict.it; enfazio@unime.it 
Materials produced are tested as catalysts for environmental applications, showing relatively high photo-degradation efficiency of methylene blue (MB) in aqueous solution under UV light irradiation.

\section{Experimental}

\subsection{Synthesis of the ZnO-based nanocolloids}

Figure 1a displays the experimental setup utilised for the synthesis of nanocolloids. The second harmonic (532 $\mathrm{nm}$ ) of a laser operating at $100 \mathrm{kHz}$ repetition rate with a pulse width of 6-8 ps was used for the ablation experiments (Fig. 1b). The laser beam was focused to a spot of about $70 \mu \mathrm{m}$ in diameter on the surface of the target with a galvanometric scanner having a telecentric objective with a focal length of $163 \mathrm{~mm}$.

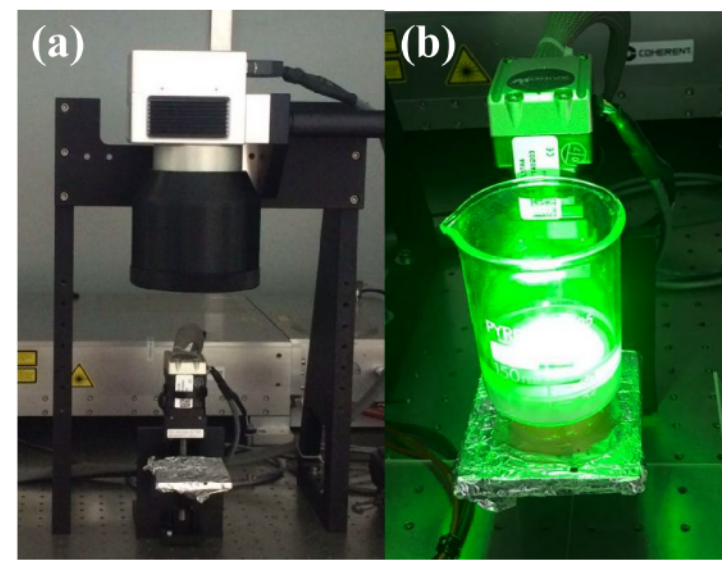

Fig. 1. (a) Experimental setup utilised for the synthesis of nanocolloids, (b) during laser irradiation.

Gold and metallic zinc targets with a thickness of 3 $\mathrm{mm}(99.99 \%$ purity) were positioned on a holder within a glass vessel and ablated in distilled water. In an experiment, the water was maintained at RT, in the other one it was heated at $80^{\circ} \mathrm{C}$ before the ps-PLA process. $\mathrm{ZnO}$ and $\mathrm{Au}$ nanocolloids were produced by separate ablation processes. The $\mathrm{ZnO}$ and $\mathrm{Au}$ targets were irradiated, at a typical laser power density of $2.0 \mathrm{~W} / \mathrm{cm}^{2}$, for $30 \mathrm{~min}$ and $5 \mathrm{~min}$, respectively. Au decorated $\mathrm{ZnO}$ nanostructures were obtained by mixing $\mathrm{ZnO}$ and $\mathrm{Au}$ colloidal solutions, in 1:1 volume ratio, immediately after their production. After preparation, all the solutions were stirred at RT in an ultrasonic bath for about $15 \mathrm{~min}$.

\subsection{Nanocolloids characterisation and photo- catalytic activity evaluation}

The morphology of the samples was investigated by scanning electron microscopy (SEM). SEM analyses were carried out with a Zeiss-Gemini 2 electron microscope, operating at $150 \mathrm{kV}$. The apparatus was coupled with a Quantax EDX spectrometer to carry out energy dispersive X-ray (EDX) analysis. The EDX detected pear-shaped dimension is about $0.7 \mu \mathrm{m}$. The crystal structures of the $\mathrm{ZnO}$ and $\mathrm{ZnO} / \mathrm{Au}$ nanocolloids were investigated by X-ray diffraction (XRD) analysis. $\mathrm{XRD}$ patterns were recorded by using using the $\mathrm{CuK}_{\alpha 1}$ wavelength $(1.5405 \AA)$ by means of a Bruker D8 Advance diffractometer. UV-vis absorption response of the $\mathrm{Au}$ and $\mathrm{ZnO}$ nanostructures was investigated by means of a Perkin-Elmer Lambda 750 UV-vis spectrometer in the 190-1100 nm range. Analyses were carried out in the colloidal phase immediately after the ablation process. Methylene blue (MB), from Sigma Aldrich, was used as a probe molecule for the preliminary evaluation of the photocatalytic activities of $\mathrm{ZnO}$ and $\mathrm{ZnO} / \mathrm{Au}$ nanostructures. The reaction was conducted in an aqueous solution containing $\mathrm{MB}$ at a $1.5 \cdot 10^{-5} \mathrm{M}$ concentration. The photocatalytic reaction was carried out, under stirring, using an UV lamp $(100 \mathrm{~W})$, emitting mainly at $365 \mathrm{~nm}$. The reaction beaker was located at a distance of about $15 \mathrm{~cm}$ from the irradiation source. The lamp energy density, measured by a power meter source, is of $30 \mathrm{~mW} / \mathrm{cm}^{2} ; 0.5 \mathrm{mg}$ of catalyst were dispersed in $3 \mathrm{ml}$ of MB aqueous solution. The photo-degradation was monitored by recording the $\mathrm{UV}-\mathrm{V}$ is spectrum during the irradiation and following the optical density at $662 \mathrm{~nm}$.

\section{Results and discussion}

Figure 2 displays the morphology of the samples as resulting from SEM analysis. Regardless of the water temperature, rounded $\mathrm{Au} \mathrm{NPs,}$ with size narrowly distributed around $9 \mathrm{~nm}$, are obtained (Fig.2a). Conversely, the morphology of $\mathrm{ZnO}$ is found to depend on the water temperature. NPs are formed at RT (not shown for briefness), whereas NRs are obtained at $80^{\circ} \mathrm{C}$ (Figs. $2 \mathrm{~b}-\mathrm{c})$. Au NPs decorate the NRs in $\mathrm{ZnO} / \mathrm{Au}$ colloids (Fig. 3).

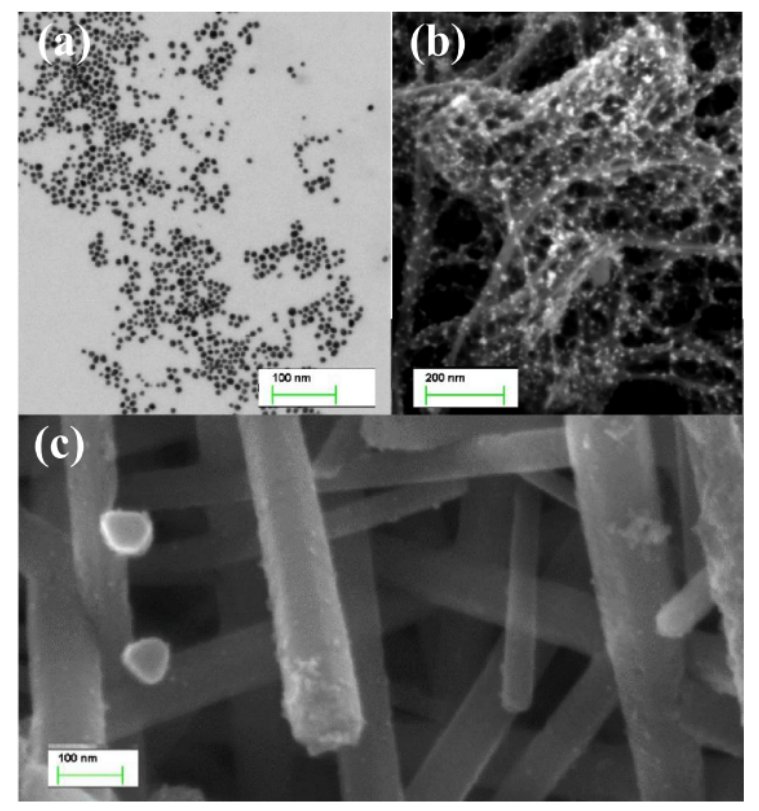

Fig. 2. SEM images of (a) Au colloids prepared at RT. Similar features characterize $\mathrm{Au}$ colloids synthesized at $80^{\circ} \mathrm{C}$. (b) $\mathrm{ZnO} / \mathrm{Au}$ colloids synthesized at $80{ }^{\circ} \mathrm{C}$; (c) a morphological detail of the sample prepared at $80^{\circ} \mathrm{C}$ at higher magnification. 


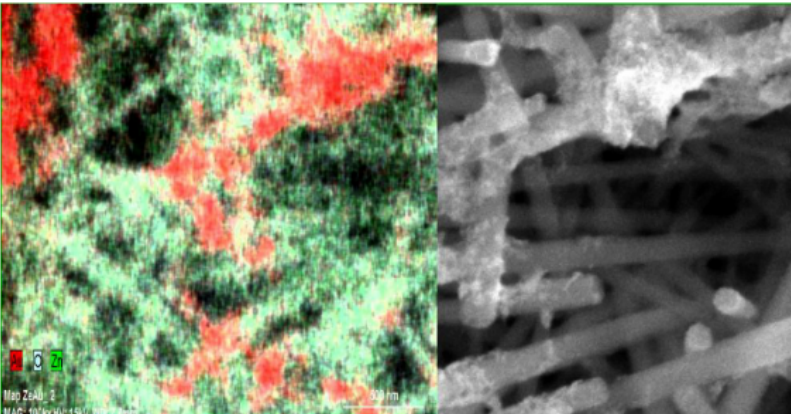

Fig. 3. Elemental dispersion in $\mathrm{ZnO} / \mathrm{Au}$ colloids synthesised at $80{ }^{\circ} \mathrm{C}$.

The samples high crystallinity, regardless of the water temperature, is evidenced by strong intensity peaks appearing in the XRD patterns (Fig. 4). The diffraction peaks can be indexed to the hexagonal wurtzite $\mathrm{ZnO}$ structure (JCPDS card No.36-1451). The mean crystallite size calculated from the most intense (101) peak by using the Scherrer's formula is $35.0 \mathrm{~nm}$.

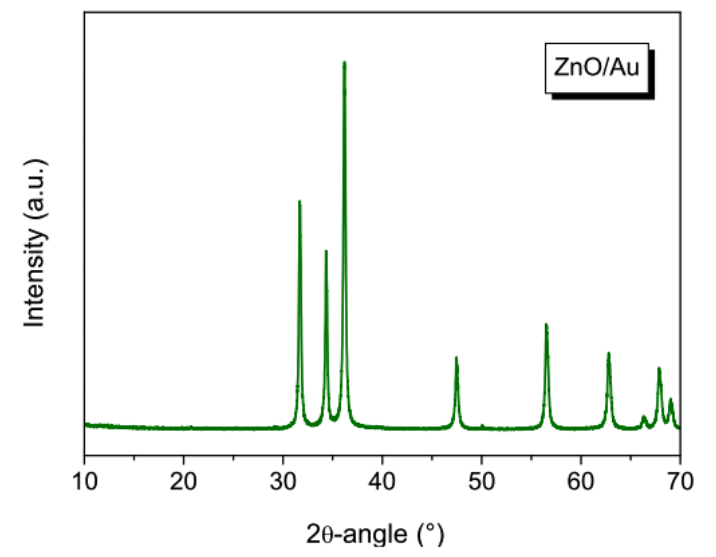

Fig. 4. XRD pattern of $\mathrm{ZnO} / \mathrm{Au}$ colloids synthesised at $\mathrm{RT}$.

The optical gap $\left(E_{\mathrm{g}}\right)$ of the synthesised colloids was estimated from their UV-Vis absorption spectra (Fig. 5), by applying to the Tauc relationship, namely $(\alpha h v)^{1 / n}=C\left(h v-E_{\mathrm{g}}\right)$, where $\alpha$ is the absorption coefficient, $C$ is a constant, $h v$ is the energy of incident photons, and $n$ an exponent whose value depends on the type of transition (the value of 2, typical of direct allowed transitions, can be used for $n$ in the case of $\mathrm{ZnO}$ and $\mathrm{ZnO} / \mathrm{Au})$. Accordingly, by plotting $(\alpha h v)^{2}$ as a function of $h v$, a linear region is observed, which denotes the onset of absorption. The extrapolation of this region to the abscissa axis yields the energy value of the optical band gap of the material. By this procedure the values of 3.31 and $3.24 \mathrm{eV}$ were found for $\mathrm{ZnO}$ and $\mathrm{ZnO} / \mathrm{Au}$ colloids, respectively. The presence of surface and intrinsic defects might be responsible for the $E_{\mathrm{g}}$ lowering with respect to the bulk $\mathrm{ZnO}(3.37 \mathrm{eV})$. Moreover, no substantial difference emerges from the comparison between $\mathrm{ZnO}$ based colloids prepared in water at RT or $80^{\circ} \mathrm{C}$.

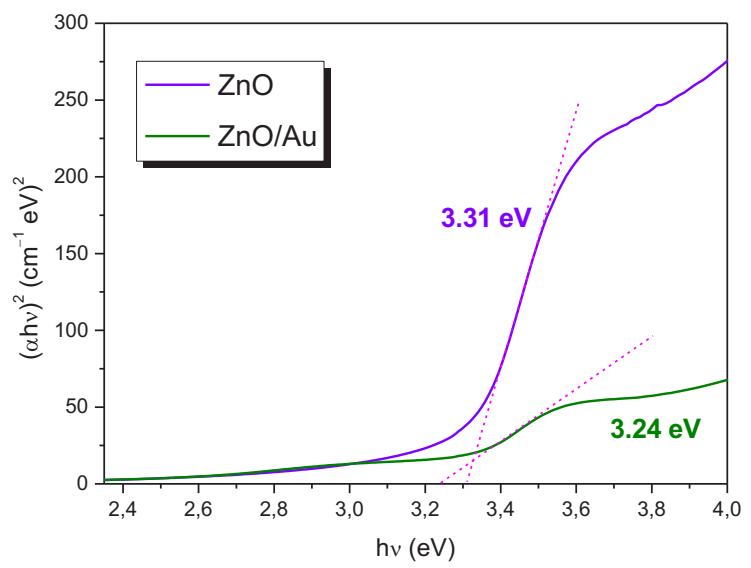

Fig. 5. Plot of $(\alpha h v)^{2}$ as a function of $h v$ in colloids prepared at RT.

In order to explore the photocatalytic activity of assynthesized $\mathrm{ZnO}$ and $\mathrm{ZnO} / \mathrm{Au}$ nanostructures towards organic pollutants, an aqueous solution containing $\mathrm{MB}$ at a $1.5 \cdot 10^{-5} \mathrm{M}$ concentration was employed as standard model water-contaminant. For this study, samples were irradiated by an UV light source emitting at $365 \mathrm{~nm}$. Under UV irradiation, the MB aqueous solution undergoes degradation and its optical absorption spectrum changes. Figure 6 shows the spectral changes produced by the $\mathrm{ZnO} / \mathrm{Au}$ photo-catalyst prepared by psPLA at $80^{\circ} \mathrm{C}$ water temperature.

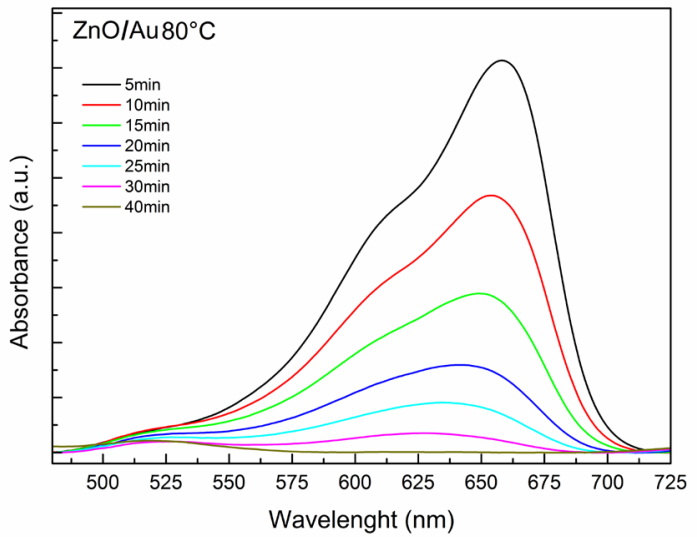

Fig. 6. Photo-degradation of $1.5 \cdot 10^{-5} \mathrm{M} \mathrm{MB}$ in presence of $\mathrm{ZnO} / \mathrm{Au}$ (water temperature at $80^{\circ} \mathrm{C}$ ) nanoparticles under UV lamp.

The characteristic absorption peak of MB appears at $662 \mathrm{~nm}$, whereas the optical response of the mixed $\mathrm{ZnO} / \mathrm{Au}$ colloids gives rise to a shoulder at $530 \mathrm{~nm}$, which is associated to $\mathrm{Au}$ characteristic plasmon resonance peak. Under UV irradiation, a decrease and a blue shift of the maximum of the absorbance take place with increasing irradiation time. The absorbance decrease is indicative of the ability of catalyst to reduce $\mathrm{MB}$, whereas the energy shift is probably due to the concomitant de-methylation of $\mathrm{MB}$ [8]. The photocatalytic process was monitored by measuring the absorbance spectra for all samples as a function of the irradiation time. Figure 7 a gives the UV irradiation time 
dependence of the relative absorbance $\left(A_{\mathrm{t}} / A_{0}\right)$, where $A_{0}$ and $A_{\mathrm{t}}$ respectively denote the initial absorbance and the absorbance at an irradiation time $t$, both measured at a wavelength of $662 \mathrm{~nm}$. In particular, from $A_{\mathrm{t}} / A_{0}$ the MB degradation percentage, $D \%$, was calculated as:

$$
D \%=\left(\frac{A_{t}}{A_{0}}-1\right) \times 100 \text {. }
$$

In addition, the semilogarithmic plot of $A_{\mathrm{t}} / A_{0}$ as a function of the irradiation time $t$ (Fig. 7b) evidences the existence of a satisfactory linear correlation between $\ln \left(A_{\mathrm{t}} / A_{0}\right)$ and $t$ in our experiments. This indicates that the kinetics of photo-bleaching can be represented as a pseudo-first order law and can be expressed by the Langmuir-Hinshelwood equation [9] as follows:

$$
\ln \left(\frac{A_{t}}{A_{0}}\right)=-k_{a} t
$$
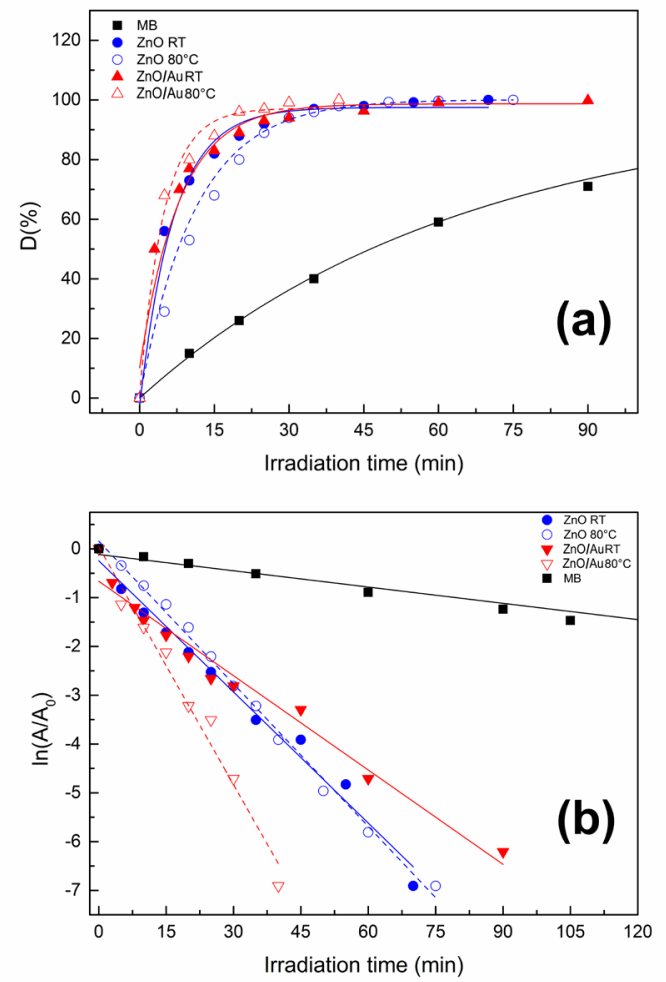

Fig. 7. (a) Photo-degradation percentage of $1.5 \cdot 10^{-5} \mathrm{M} \mathrm{MB}$ under UV irradiation; (b)The linear fitting of $\ln \left(A_{t} / A_{0}\right)$ versus irradiation time $(\mathrm{t})$.

From the linear fitting to the $\ln \left(A_{\mathrm{t}} / A_{0}\right)$ versus $t$ data (Fig. $7 \mathrm{~b})$, the rate constant $\left(k_{\mathrm{a}}\right)$ can be directly obtained. The values of $k_{\mathrm{a}}$ inferred from the fitting procedure as well as the degradation percentage of $\mathrm{MB}$ after $15 \mathrm{~min}$ of reaction and the time necessary to reach the $50 \%$ of the MB degradation $\left(t_{1 / 2}\right)$, are reported in Table 1 . The data reported in Table 1 prove that, under UV irradiation, all the synthesised nanostructures show a photo-catalytic activity towards the selected dye molecules with the highest $k_{\mathrm{a}}$ value $\left(0.162 \mathrm{~min}^{-1}\right)$, pertaining to $\mathrm{Au}$ decorated $\mathrm{ZnO}$ nanorods $\left(\mathrm{ZnO} / \mathrm{Au} 80^{\circ} \mathrm{C}\right)$. This value is 14 times higher than that obtained for the MB photodegradation in absence of any catalysts, and 1.6 times higher than for $\mathrm{ZnO}$ nanorods $\left(\mathrm{ZnO} 80^{\circ} \mathrm{C}\right)$.
Table 1. Photo-degradation rate constants of $\mathrm{MB}$ with different catalysts using $\ln \left(\mathrm{A}_{\mathrm{t}} / \mathrm{A}_{0}\right)=k_{\mathrm{a}} \mathrm{t}$ as fitting equation model, $\mathrm{R}$-square value $\mathrm{R}^{2}$, degradation percentage (D\%) of $\mathrm{MB}$ and time $\left(t_{1 / 2}\right)$ for $\mathrm{D} \%=50 \%$.

\begin{tabular}{|l|c|c|c|c|}
\hline Sample & $\begin{array}{c}k_{\mathrm{a}} \\
\left(\mathrm{min}^{-1}\right)\end{array}$ & $\mathrm{R}^{2}$ & $\begin{array}{c}\mathrm{D} \% \\
(\mathrm{t}=15 \mathrm{~min})\end{array}$ & $\begin{array}{c}\mathrm{t}_{1 / 2} \\
(\mathrm{~min})\end{array}$ \\
\hline $\mathrm{MB}$ & 0.011 & 0.99 & 19.96 & 46 \\
\hline $\mathrm{ZnO} \mathrm{RT}$ & 0.089 & 0.98 & 81.61 & 5 \\
\hline $\mathrm{ZnO} 80^{\circ} \mathrm{C}$ & 0.097 & 0.99 & 68.23 & 7 \\
\hline $\mathrm{ZnO} / \mathrm{Au} \mathrm{RT}$ & 0.064 & 0.97 & 82.49 & 3 \\
\hline $\mathrm{ZnO} / \mathrm{Au} 80^{\circ} \mathrm{C}$ & 0.162 & 0.98 & 89.21 & 3 \\
\hline
\end{tabular}

The calculated $k_{\mathrm{a}}$ values confirm that Au NPs act as effective catalysts in the reduction of $\mathrm{MB}$ under UV irradiation. Moreover, the presence of Au NPs on the surface of $\mathrm{ZnO}$ nanorods (as proven by STEM images) is probably responsible for the improved photo-catalytic activity (i.e. increase of photo-degradation rate) of the $\mathrm{ZnO} / \mathrm{Au}$ sample. This behaviour is explained in terms of a "doping action" of $\mathrm{Au}$ nanoparticles on the photocatalytically active metal oxides. The accepted mechanism for the enhancement is the transfer of the excited electrons from the $\mathrm{ZnO}$ conduction band to the $\mathrm{Au}$ nanoparticles. Trapping of the electrons on the $\mathrm{Au}$ particles then slows down the recombination process [10].

\section{Conclusion}

$\mathrm{ZnO}$ and $\mathrm{Au}$ nanocolloids were successfully synthesised by picosecond pulsed laser ablation, using $\mathrm{Zn}$ and $\mathrm{Au}$ metallic targets, in water media at $\mathrm{RT}$ and $80^{\circ} \mathrm{C}$. $\mathrm{ZnO}$ and $\mathrm{Au}$ nanoparticles were formed at RT with size in the $10-50 \mathrm{~nm}$ range, while $\mathrm{ZnO}$ nanorods were obtained when water was maintained at $80^{\circ} \mathrm{C}$ during the ablation process. By adding $\mathrm{Au}$ NPs to $\mathrm{ZnO}$ colloids after the ablation process, Au-decorated $\mathrm{ZnO}$ nanorods were attained. Under UV irradiation, all the produced nanostructures show a photo-catalytic activity towards the used dye molecule. An improvement of the catalytic efficiency was observed in the presence of Au NPS, specially when $\mathrm{ZnO}$ sample was characterized by welldefined nanorod structures.

\section{References}

1. V. Binas, D. Venieri, D. Kotzias, G. Kiriakidis, Journal of Materiomics, 3 (1), 3 (2017)

2. M. Anijum, R. Miandad, M. Waqas, F. Gehany, M.A. Barakat, Ar. J. of Chemistry, (to be published)

3. Y.S. Song, N.I. Cho, M.H. Lee, B.Y. Kim, D.Y. Lee, J Nanosci. Nanotechnol. 16 (2), 1831 (2016)

4. C. Wang, J. Lu, L. Zhou, J. Li, J. Xu, W. Li, L. Zhang, X. Zhong, T. Wang, PLoS One. 11(10), e0164434 (2016)

5. M. T. Amin, A. A. Alazba, and U. Manzoor, AdV in Mat. Sci. and Eng., 24, 6 (2014) 
6. C. Chen, J. Liu, P. Liu, B. Yu, Advances in Chem.Eng. and Sci., 1, 9 (2011)

7. J. Manna, T.P. Vinod, K.Flomin, R. Jelinek, J. Colloid and Interface Sci. 460, 113 (2015)

8. T. Zhang, T. Oyama, A. Aoshima, H. Hidaka, J. Zhao, N. Serpone J. Photochem. Photobio. A Chem 140, 163 (2001)

9. A. Nezamzadeh-Ejhieh, H. Z. Mobarakeh, J. of Ind. and Eng.Chem., 20 (4) 1421 (2014).

10. K.-J. Kim, . B. Kreider, C.-H. PChang, C.-M. Park, H.-G. Ahn, J. Nanopart. Res. 15, 1 (2013). 